\title{
Measuring body core temperature using a novel non-invasive sensor
}

\author{
Yoram Epstein ${ }^{1,2^{*}}$, Savyon Mazgaoker ${ }^{1}$, Doron Gruber ${ }^{1}$, Daniel S Moran ${ }^{3}$, Ran Yanovich', Itay Ketko ${ }^{1}$, Yuval Heled ${ }^{1,2}$ \\ From 15th International Conference on Environmental Ergonomics (ICEE XV) \\ Portsmouth, UK. 28 June - 3 July 2015
}

\section{Introduction}

In various jobs workers may be exposed to extreme environmental conditions and physical activities. Under these conditions it is imperative to follow body temperature in workers in order to protect them from overheating leading to heat related injuries. The Dräger Double Sensor (DS) is a novel non-invasive device based on heat flux balance approach for the assessment of body core temperature [1]. The purpose of this study was to compare DS measurements to rectal temperatures and to evaluate the agreement between the two measurements.

\section{Methods}

17 male subjects dressed in shorts performed the following experimental protocol: 30 min rest under thermal comfort conditions, $30 \mathrm{~min}$ rest under hot climate $\left(40{ }^{\circ} \mathrm{C}, 40 \% \mathrm{rh}\right)$ and $60 \mathrm{~min}$ of exercise under the hot climatic conditions. Continuous measurements were obtained with the DS $\left(\mathrm{T}_{\mathrm{DS}}\right)$ in parallel to rectal temperature $\left(\mathrm{T}_{\mathrm{re}}\right)$ (YSI-401 thermistor).

\section{Results}

During rest under comfortable climatic conditions $T_{D S}$ tended to be lower than $\mathrm{T}_{\text {re }}$ (Figure 1). During heat exposure, mean $\mathrm{T}_{\mathrm{DS}}$ was within $+0.3{ }^{\circ} \mathrm{C}$ of mean $\mathrm{T}_{\mathrm{re}}$. $\mathrm{A}$ good linear correlation $(r=0.99)$ between the $T_{D S}$ and $T_{r e}$ during exercise in the heat was found, which enabled to adjust $\mathrm{T}_{\mathrm{DS}}$. A scatter plot of Temperature residuals $\left(\mathrm{T}_{\mathrm{re}}-\mathrm{T}_{\mathrm{DS}}\right)$ of the corrected data was within $\pm 0.5{ }^{\circ} \mathrm{C}$ of mean residual (Figure 2).

\footnotetext{
* Correspondence: Yoram.Epstein@sheba.health.gov.l

${ }^{1}$ Heller Institute of Medical Research, Sheba Medical Center, Tel Hashomer, Israel

Full list of author information is available at the end of the article
}

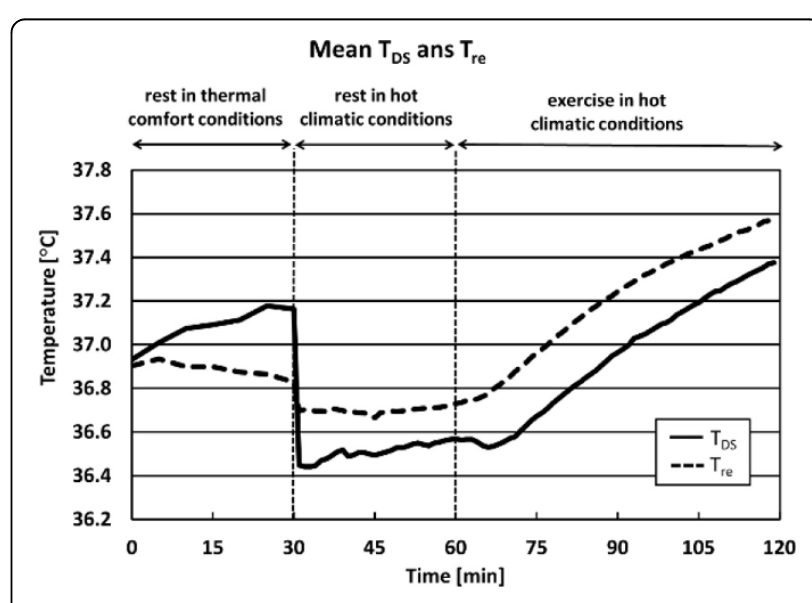

Figure 1

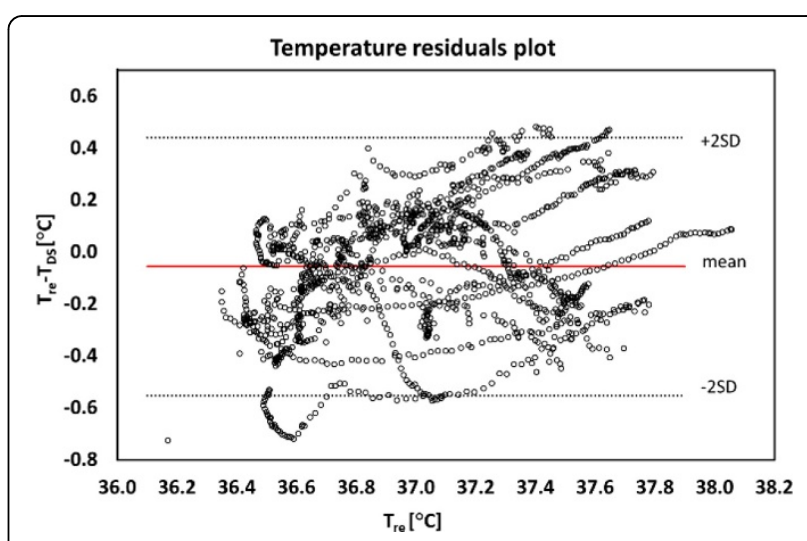

Figure 2

\section{Discussion}

$\mathrm{T}_{\mathrm{DS}}$ is within a reasonable range from the "gold standard" $\left(\mathrm{T}_{\mathrm{re}}\right)$ during heat stress. It seems that $\mathrm{T}_{\mathrm{DS}}$ equilibrates slower than $\mathrm{T}_{\mathrm{re}}$ and, therefore, the agreement between 
the two measurements is low during the first part of the exposure (30 minutes).

\section{Conclusion}

The results are promising for potential use of the DS in workers under field conditions, especially under environmental heat stress and when dressed in protective garments. Further investigations are required to validate the data under various conditions (e.g. higher heat stress).

\section{Authors' details}

${ }^{1}$ Heller Institute of Medical Research, Sheba Medical Center, Tel Hashomer, Israel. ${ }^{2}$ Sackler Faculty of Medicine, Tel Aviv University, Tel Aviv, Isreal. ${ }^{3}$ Ariel University and Washington College of Education, Israel.

Published: 14 September 2015

\section{Reference}

1. Gunga HC, Sandsund M, Reinertsen RE, Sattler F, Koch J: A non-invasive device to continuously determine heat strain in human. $J$ Thermal Biol 2008, 33:297-307.

doi:10.1186/2046-7648-4-S1-A28

Cite this article as: Epstein et al:: Measuring body core temperature using a novel non-invasive sensor. Extreme Physiology \& Medicine 2015 4(Suppl 1):A28.
Submit your next manuscript to BioMed Central and take full advantage of:

- Convenient online submission

- Thorough peer review

- No space constraints or color figure charges

- Immediate publication on acceptance

- Inclusion in PubMed, CAS, Scopus and Google Scholar

- Research which is freely available for redistribution

Submit your manuscript at www.biomedcentral.com/submit 